\title{
DEMONSTRATIVOS NA ROMÂNIA NOVA: PORTUGUÊS BRASILEIRO $\times$ ESPANHOL MEXICANO (DADOS DE DIÁLOGOS ENTRE INFORMANTE E DOCUMENTADOR)
}

\author{
César Nardelli Cambraia* \\ Resumo: Os sistemas de demonstrativos em línguas \\ românicas apresentam de forma geral uma tendência \\ ao binarismo, embora essa tendência não seja atingida \\ através dos mesmos caminhos e os resultados não sejam \\ idênticos. No presente trabalho, analisam-se os \\ demonstrativos em dados de língua falada extraídos de \\ diálogos entre informante e documentador do Projeto \\ NURC de quatro cidades brasileiras e da cidade do \\ México e demonstra-se a presença da referida tendência \\ ao binarismo em ambos os domínios linguísticos. \\ Palavras-chave: Lingüística românica; demonstrativos; \\ português brasileiro; espanhol mexicano; língua falada.
}

\section{Demonstrativos}

Tradicionalmente a linguística românica tem se ocupado do estudo comparado das línguas românicas das variedades sejam europeias sejam não europeias. Frequentemente, porém, a ênfase tem recaído na relação entre estas e aquelas, mas raramente se analisa a relação das variedades românicas não-europeias entre si. O presente estudo tem como objetivo contribuir para o preenchimento dessa lacuna de estudos comparados sobre variedades românicas não-europeias.

* Universidade Federal de Minas Gerais / CNPq. 
Como lembram Cambraia e Bianchet, ${ }^{1}$ os demonstrativos em línguas românicas de forma geral apresentam uma tendência ao binarismo, mas historicamente o resultado dessa tendência não tem sido alcançado pelos mesmos caminhos. No português brasileiro, como havia assinalado Câmara Jr., ${ }^{2}$ há uma tendência de fixação de um sistema binário composto de esse $\times$ aquele $;^{3}$ já no espanhol mexicano, segundo informou Kany, ${ }^{4}$ esse sistema seria formado por este $\times$ ese, uma vez que haveria a tendência de utilizar ese no lugar de aquel.

Para compreender melhor essa questão, apresenta-se aqui um estudo dos demonstrativos em variedades faladas urbanas cultas do português brasileiro (PB) e do espanhol mexicano (EM).

\section{Método}

Para investigar comparativamente a tendência ao binarismo no PB e no EM, fez-se uma coleta de dados extraídos do Projeto NURC. ${ }^{5}$ Coletaram-se todas as ocorrências de demonstrativos nos inquéritos que consistiam em diálogos ${ }^{6}$ entre informante e documentador referentes a informantes do sexo masculino da $1^{\mathrm{a}}$

${ }^{1}$ CAMBRAIA; BIANCHET. Caleidoscópio latino-românico: demonstrativos.

${ }^{2}$ CÂMARA JR. História e estrutura da língua portuguesa, p. 103-104.

${ }^{3}$ Nascentes havia proposto que entre este e esse prevaleceria o primeiro. (NASCENTE. Êste, esse, p. 5).

${ }^{4}$ KANY. Sintaxis hispanoamericana, p. 170.

${ }^{5}$ BLANCH. El habla de la ciudad de México; PRETI; URBANO. A linguagem falada culta na cidade de São Paulo; CALLOU; LOPES. A linguagem falada culta na cidade do Rio de Janeiro; MOTA; ROLLENBERG. A linguagem falada culta na cidade de Salvador; HILGERT. A linguagem falada culta na cidade de Porto Alegre.

${ }^{6}$ Esses diálogos podem ser interpretados como dirigidos, pois foi o documentador quem guiou de forma geral os temas da entrevista com base nas perguntas que fez. Do ponto de vista tipológico, predomina nos diálogos a descrição, seguida em menor escala de narrativa e, muito raramente, de argumentação. 
faixa etária ( 25 a 35 anos). Aceitando a ideia de que a gramática dos falantes reflete o estado da língua quando tinham em torno de 15 anos, ${ }^{7}$ os dados em questão, extraídos de inquéritos realizados por volta de fins da década de 1960 e princípios da de 1970, refletiriam a situação linguística de fins da década de 1950 e princípios da de 1960. As informações referentes aos inquéritos analisados aparecem sintetizadas no quadro abaixo:

QUADRO 1

Caracterização dos inquéritos

\begin{tabular}{|c|c|c|c|c|c|c|}
\hline Diálogo & Cidade & Sexo & Idade & Profissão & Tema & $\begin{array}{l}\text { Data e tempo } \\
\text { de gravação }\end{array}$ \\
\hline $\begin{array}{l}\text { SSA/ } \\
\text { DID277 }\end{array}$ & Salvador & Masc. & 30 & $\begin{array}{l}\text { Engenheiro } \\
\text { agrônomo }\end{array}$ & $\begin{array}{l}\text { Transportes } \\
\text { e viagens }\end{array}$ & $\begin{array}{c}1977 \\
40 \text { mins. }\end{array}$ \\
\hline $\begin{array}{l}\text { SSA/ } \\
\text { DID138 }\end{array}$ & Salvador & Masc. & 31 & $\begin{array}{l}\text { Professor univers., } \\
\text { área de Matemática }\end{array}$ & $\begin{array}{l}\text { Cinema e } \\
\text { televisão }\end{array}$ & $\begin{array}{c}1975 \\
40 \text { mins. }\end{array}$ \\
\hline $\begin{array}{l}\mathrm{RJ} / \\
\mathrm{DID} 012\end{array}$ & R.Janeiro & Masc. & 29 & $\begin{array}{l}\text { Formação univers. } \\
\text { em Direito }\end{array}$ & $\begin{array}{l}\text { Vida social } \\
\text { e diversões }\end{array}$ & $\begin{array}{c}1971 \\
65 \text { mins. }\end{array}$ \\
\hline $\begin{array}{l}\text { SP/ } \\
\text { DID018 }\end{array}$ & S. Paulo & Masc. & 31 & Advogado & $\begin{array}{l}\text { Casa, terreno, } \\
\text { vegetais, } \\
\text { agricultura, } \\
\text { animais e gado }\end{array}$ & $\begin{array}{c}1971 \\
45 \text { mins. }\end{array}$ \\
\hline $\begin{array}{l}\text { SP/ } \\
\text { DID161 }\end{array}$ & S. Paulo & Masc. & 25 & Publicitário & $\begin{array}{l}\text { Teatro, televisão, } \\
\text { rádio, cinema } \\
\text { e vestuário }\end{array}$ & $\begin{array}{c}1974 \\
65 \text { mins. }\end{array}$ \\
\hline $\begin{array}{l}\text { POA/ } \\
\text { DID008 }\end{array}$ & P. Alegre & Masc. & $25-35$ & Advogado & $\begin{array}{l}\text { Profissões e } \\
\text { ofícios; tempo } \\
\text { cronológico }\end{array}$ & $\begin{array}{c}1971 \\
40 \text { mins. }\end{array}$ \\
\hline $\begin{array}{l}\text { POA/ } \\
\text { DID009 }\end{array}$ & P. Alegre & Masc. & $25-35$ & Dentista & Corpo humano & $\begin{array}{c}1972 \\
35 \text { mins. }\end{array}$ \\
\hline $\begin{array}{l}\text { MX/ } \\
\text { DID092 }\end{array}$ & México & Masc. & 26 & Contador público & $\begin{array}{l}\text { Campo da natação, } \\
\text { alguns aspectos } \\
\text { da profissão }\end{array}$ & $\begin{array}{l}(c a .1968)^{8} \\
30 \text { mins. }\end{array}$ \\
\hline $\begin{array}{l}\text { MX/ } \\
\text { DID138 }\end{array}$ & México & Masc. & 25 & $\begin{array}{l}\text { Engenheiro } \\
\text { químico }\end{array}$ & $\begin{array}{l}\text { Indústria } \\
\text { química }\end{array}$ & $\begin{array}{l}(c a .1968) \\
60 \text { mins. }\end{array}$ \\
\hline
\end{tabular}

${ }^{7}$ MOLLICA; BRAGA. Introdução à sociolingüística: o tratamento da variação, p. 44. ${ }^{8}$ Não se informa a data de coleta de cada amostra no volume com sua transcrição (BLANCH. El babla de la ciudad de México, p. 11 e 21), mas, por dados na própria amostra, infere-se que tenha sido por volta de 1968. 
O quadro acima permite ver que não há uma correspondência perfeita entre as características da amostra disponível para cada cidade: p. ex., os dados de SSA são de pessoas apenas fora da área de humanidades (engenheiros), enquanto os de SP são de pessoas exclusivamente dessa área (advogado e publicitário); os temas variam muito, desde mais leves (vida social) até mais técnicos (corpo humano); a duração também não é uniforme, variando de 30 minutos (MX/DID092) até 65 minutos (RJ/DID012); para os dados do RJ, há transcrição de apenas um informante do sexo masculino (o que acabou sendo compensado, parcialmente, pelo fato de a duração de sua entrevista ter sido uma das mais longas). Apesar desses limites, não se pode negar a relevância desses dados para uma análise linguística, já que foram coletados com os devidos cuidados justamente para essa finalidade.

Depois de coletados todos os dados de cada entrevista, separaram-se primeiramente os dos documentadores ${ }^{9}$ (que não foram analisados) e os dos informantes. Dos dados dos informantes, foram separados todos aqueles que constituíam busca lexical ou truncamento, geralmente fruto do processo de formulação da mensagem: em seção própria ao final deste trabalho serão comentados. Especificamente nos dados relativos ao EM apareceu um uso particular dos demonstrativos em função fática: esses dados também foram separados dos demais e serão comentados em seção própria.

\footnotetext{
${ }^{9}$ Os dados dos documentadores indicam que não atuaram exatamente da mesma maneira no processo, variando entre casos de menor e maior presença durante a entrevista. A ocorrência de demonstrativos na fala dos documentadores por entrevista foi a seguinte: MX/DID092: 0 oc.; MX/DID138: 39 ocs.; SSA/DID277: 36 ocs.; SSA/DID138: 45 ocs.; RJ/DID012: 15 ocs.; SP/DID018: 47 ocs.; SP/ DID161: 13 ocs.; POA/DID008: 2 ocs.; e POA/DID008: 4 ocs.
} 


\section{Descrição e análise dos dados}

\subsection{Frequência por forma}

Para oferecer uma visão mais ampla do sistema de demonstrativos no corpus analisado, convém apresentar inicialmente uma tabela com a frequência distribuída segundo as diferentes formas $(\mathrm{F} 1=$ este e flexões, $\mathrm{F} 2=e s(s) e$ e flexões, $\mathrm{e}$ $\mathrm{F} 3=\operatorname{aquel}(e)$ e flexões):

TABELA 1

Frequência por forma

\begin{tabular}{l|r|r|r|r}
\hline Forma & \multicolumn{1}{|c|}{ F1 } & F2 & F3 & \multicolumn{1}{c}{ Total } \\
\hline NURC/SSA & - & $65(60 \%)$ & $44(40 \%)$ & $109(100 \%)$ \\
\hline NURC/RJ & - & $55(71 \%)$ & $23(29 \%)$ & $78(100 \%)$ \\
\hline NURC/SP & $1(1 \%)$ & $82(71 \%)$ & $33(28 \%)$ & $116(100 \%)$ \\
\hline NURC/POA & $4(3 \%)$ & $97(76 \%)$ & $26(20 \%)$ & $127(100 \%)$ \\
\hline NURC/BR & $5(1 \%)$ & $299(70 \%)$ & $126(29 \%)$ & $430(100 \%)$ \\
\hline NURC/MX & $23(17 \%)$ & $112(82 \%)$ & $1(1 \%)$ & $136(100 \%)$ \\
\hline
\end{tabular}

Analisando os dados do português por cidade, verificam-se: (a) a ausência de F1 nos dados de SSA e RJ e sua baixíssima frequência em SP e POA; (b) forte predominância de F2 em todas as cidades; e (c) a mesma hierarquia F2 $>$ F3 $>$ F1 em todas as cidades. Observando detidamente a diferença entre as cidades, nota-se um curioso padrão de gradualidade: quanto mais ao sul, mais F1/F2 e menos F3. Examinando os dados do PB conjuntamente (NURC/BR), verifica-se quase uma repetição dos padrões por cidade: pouco F1, mais F2 e a hierarquia $\mathrm{F} 2>\mathrm{F} 3>\mathrm{F} 1$. Esses dados indicam proceder a proposta de Câmara Jr., ${ }^{10}$ de que há uma tendência no PB de se implementar um sistema binário composto de esse $\times$ aquele $(\mathrm{F} 2 \times \mathrm{F} 3)$.

Considerando a ausência de evidências convincentes sobre quantas ocorrências de demonstrativos são necessárias para se ter uma visão representativa do sistema em uso, convém verificar

${ }^{10}$ CÂMARA JR. História e estrutura da língua portuguesa, p. 103-104. 
se os dados aqui apurados para o português são compatíveis com os de outros estudos ${ }^{11}$ sobre o mesmo tema.

No estudo de Pavani ${ }^{12}$ sobre 1.258 dados do NURC/SP (oriundos de três tipos ${ }^{13}$ de inquérito, de informantes de sexo masculino e feminino, de três faixas etárias ${ }^{14}$ ) extraídos de 10 inquéritos, ${ }^{15}$ as frequências encontradas foram: $\mathrm{F} 1=12 \%$, $\mathrm{F} 2=64 \%$ e F3 $=24 \%$. Embora a hierarquia de frequência do estudo de Pavani e a do presente estudo para SP seja a mesma (F2 > F3 > F1), o valor de frequência por forma é distinto (cf., p. ex., os valores de F1). Restringindo, porém, os dados de Pavani, a apenas os de DIDs (com 303 dados), têm-se um resultado ( $\mathrm{F} 1=3 \%$, $\mathrm{F} 2=77 \%$ e F3 $=19 \%$ ) mais próximo ao obtido na presente pesquisa em relação a $\mathrm{F} 1$, mas para $\mathrm{F} 2$ e $\mathrm{F} 3$ as frequências não só se modificaram com a restrição (F2, de $64 \%$ para $77 \%$; F3, de $24 \%$ para 19\%) como ainda se mantêm um pouco distantes dos resultados encontrados aqui ( $\mathrm{F} 2=70 \%$ e F3 $=29 \%$ ).

No estudo de Roncarati ${ }^{16}$ sobre duas amostras do $\mathrm{RJ}^{17}$ (Amostra 80, coletada entre 1980 e 1984; e Amostra 00, coletada

\footnotetext{
${ }^{11}$ Em muitos estudos, não é apresentada a frequência geral já quantificada, mas tal dado é possível de passível de ser obtido contabilizando-se os números informados nesses estudos.

${ }^{12}$ PAVANI. Os demonstrativos este, esse $\boldsymbol{e}$ aquele no português culto falado em São Paulo.

${ }^{13}$ A saber: DID (diálogo entre informante e documentador), $\mathrm{D}_{2}$ (diálogo entre informantes) e EF (elocuções formais).

${ }^{14}$ A saber: $1^{\text {a }}$ (25 a 35 anos), $2^{\text {a }}$ (36 a 55 anos) e $3^{\text {a }}(56$ anos ou mais).

${ }^{15}$ SP/DID032 (H1 $\left.{ }^{\mathrm{a}}\right)$, SP/DID214 (H3 $)$, SP/DID041 (M11), SP/DID011 (M2a); SP/ $\mathrm{D}_{2} 255\left(\mathrm{H} 2^{\mathrm{a}}\right), \mathrm{SP} / \mathrm{D}_{2} 390\left(\mathrm{M}^{\mathrm{a}}\right), \mathrm{SP} / \mathrm{D}_{2} 333\left(\mathrm{M}^{\mathrm{a}}\right)$; SP/EF338 (H1 $\left.{ }^{\mathrm{a}}\right), \mathrm{SP} / \mathrm{EF} 365\left(\mathrm{H} 2^{\mathrm{a}}\right)$, $\mathrm{SP} / \mathrm{EF} 153\left(\mathrm{H} 3^{\mathrm{a}}\right)$.

${ }^{16}$ RONCARATI. Os mostrativos na variedade carioca falada.

${ }^{17}$ Um estudo anterior sobre demonstrativos no português do Rio de Janeiro é o de CID, COSTA e OLIVEIRA (Este e esse na fala culta do Rio de Janeiro), baseado em 2687 dados do NURC/RJ, extraídos dos três tipos de inquérito. Em função da abordagem mais qualitativa adotada pelas autoras, não houve a apresentação
} 
entre 1999 e 2000), verificam-se as seguintes frequências: Amostra 80 (1556 dados), F1 = 0,7\%, F2 = 71,5\% e F3 = 27,8\%; Amostra 00 (2058 dados), $\mathrm{F} 1=0,3 \%, \mathrm{~F} 2=72,2 \%$ e F3 $=27,6 \%$. Como se vê, são bastante próximas às encontradas na presente pesquisa para os dados do RJ, diferindo apenas pela ausência de F1 na presente pesquisa e sua presença, quase residual, naquela.

Por fim, há ainda o estudo de Castilho ${ }^{18}$ sobre um corpus compartilhado do NURC de cinco cidades (Recife, Salvador, Rio de Janeiro, São Paulo e Porto Alegre) com uma amostra de cada um dos três tipos de inquérito, ${ }^{19}$ no qual se coletaram 214 dados, distribuídos dados de Castilho não estejam tão próximos dos da presente pesquisa para o Brasil conjuntamente (cf. NURC/BR), percebem-se igualmente o predomínio de F2 e a mesma hierarquia F2 $>$ F3 $>$ F1.

A comparação dos resultados apurados na presente pesquisa com os dos três estudos citados apresenta certamente semelhança nos aspectos fundamentais (pouco F1, mais F2 e hierarquia F2 > F3 > F1), mas as frequências não coincidem totalmente. Uma primeira explicação seria a diferença dos tipos de inquérito dos corpora (a diferença nos dados gerais frente aos de DIDs ambos de Pavani aqui apurada confirma essa hipótese), mas não se pode ignorar o problema da falta de descrição precisa do método de coleta nos três referidos estudos, pois esse problema abre a possibilidade de que as diferenças decorram do tipo de dado que foi contabilizado (p. ex.: contabilizaram-se os dados de truncamento?). De qualquer maneira, a prudência sugere

de uma frequência geral por forma, razão pela qual não é possível comparar esses dados com os da presente pesquisa. Do ponto de vista metodológico, porém, é interessante salientar terem verificado que os demonstrativos foram mais frequentes nos DIDs (CID; COSTA; OLIVEIRA. Este e esse na fala culta do Rio de Janeiro, p. 200), justamente o tipo adotado na presente pesquisa.

${ }^{18}$ CASTILHO. Os mostrativos no português falado.

${ }^{19}$ REC/DID131, SSA/DID231, RJ/DID328, SP/DID234, POA/DID045; REC/D 005, $\mathrm{SSA} / \mathrm{D}_{2}$ 098, RJ/D $355, \mathrm{SP} / \mathrm{D}_{2} 369, \mathrm{POA} / \mathrm{D}_{2} 291 ; \mathrm{REC} / \mathrm{EF} 337, \mathrm{SSA} / \mathrm{EF} 049, \mathrm{RJ} / \mathrm{EF} 379$, SP/EF405, POA/EF278. 
interpretar-se o presente estudo como exploratório, sendo seu principal objetivo o de identificar as questões mais centrais que devem ser testadas em corpora mais amplos.

Passando agora aos dados do EM (NURC/MX), verificamse: (a) a frequência quase nula de F3; (b) o predomínio de F2; e (c) a hierarquia F2 $>$ F1 $>$ F3. Esses dados indicam proceder a descrição de Kany, ${ }^{20}$ segundo a qual há uma tendência no EM de substituir aquel por ese (F3 por F2) em diversas circunstâncias.

$O$ contraste entre os dados do PB e do EM revela coincidências interessantes: a tendência a abandono de uma das formas (F1 no PB e F3 no EM) e o predomínio nítido de F2 (em ambos).

A tendência ao binarismo tem se manifestado em diferentes sistemas de demonstrativos românicos originalmente ternários, como o catalão, o occitânico e o italiano (línguas como o francês, o reto-romano e o romeno parecem já ter apresentado um sistema binário desde sua origem). Ainda que o binarismo em si não seja uma novidade no universo românico, é interessante verificar uma particularidade nesse processo: no caso do catalão e do italiano, a forma que tende(u) ao desaparecimento é a tradicionalmente vinculada à $2^{\text {a }}$ pessoa (respectivamente, aqueix e codesto), no caso do occitânico e do PB é a da $1^{\mathrm{a}}$ (respectivamente, aiceste e este) e no caso do EM é a da $3^{\mathrm{a}}$ (aquel). Em síntese, embora a tendência pareça ser uma só (o binarismo), os caminhos para implementá-la têm sido diferentes.

O predomínio de F2 tanto no PB quanto no EM é uma questão complexa. No caso do $\mathrm{PB}$, o predomínio constatado poderia ser fruto da natureza do corpus adotado, ${ }^{21}$ no qual os demonstrativos

\footnotetext{
${ }^{20}$ KANY. Sintaxis hispanoamericana, p. 170.

${ }^{21}$ A propósito da variação no uso dos demonstrativos de acordo com o corpus, CAMBRAIA et al. (Variação, mudança e estilística: demonstrativos) verificaram que em diferentes obras de um mesmo gênero e de um mesmo autor brasileiro, escritas entre 1986 e 2006, o padrão de distribuição dos demonstrativos apresenta fortes diferenças, sugerindo ser um aspecto linguístico suscetível a intervenções das mais diferentes ordens (desde hipercorreção até padronização segundo cada
} 
aparecem predominantemente na função endofórica, estabelecendo coesão referencial pela retomada de informação citada geralmente logo antes (caso em que $\mathrm{F} 3$ dificilmente seria usado). Já no caso do $\mathrm{EM}$, tanto $\mathrm{F} 1$ quanto $\mathrm{F} 2$ poderiam, em tese, ser efetivamente utilizados para a referida função endofórica, igualmente predominante nesse corpus, mas, ainda assim, a forma preferida foi F2. É interessante lembrar que, do ponto de vista histórico, F2 deriva do pronome de identidade ipse, constituído originalmente do anafórico is somado ao morfema pse, ou seja, originalmente F2 atuava como um anafórico que reforçava uma relação de identidade com o antecedente, função muito similar à que sua continuação histórica apresenta intensivamente no corpus analisado. ${ }^{22}$

\subsection{Frequência por gênero}

Uma estratégia interessante para avaliar se determinadas formas estão perdendo sua vitalidade (como seria o caso de F1 no PB e F3 no EM) é examinar se há uma tendência de sua restrição a certos padrões, como, por exemplo, sua utilização em apenas um dado gênero gramatical. Para verificar se isso está ocorrendo nos

casa editorial no caso de textos impressos). Considerando que, como demonstrou Cambraia (O caos na norma: demonstrativos em gramáticas tradicionais), mesmo as gramáticas tradicionais não apresentam uma normatização unitária e coerente para o emprego dos demonstrativos, pode-se chegar à conclusão de que, quanto menos espontâneo for o corpus utilizado para o estudo dos demonstrativos, maior a probabilidade de se encontrarem padrões irregulares de distribuição, fato já salientado por Labov (LABOV. Language in the inner city, p. 208) ao defender a prioridade do estudo do vernáculo em análises linguísticas.

${ }^{22}$ Essa prevalência atual de F2 opõe-se nitidamente à situação de textos medievais. $\mathrm{Na}$ tradução portuguesa e espanhola da obra ascética Livro de Isaac (em que também predomina o uso endofórico), F1 é claramente predominante: na sua versão do códice alcobacense da tradução portuguesa, as frequências são F1 = 57\%, $\mathrm{F} 2=1 \%$ e F3 = 42\% em um universo de 997 dados (CAMBRAIA. Livro de Isaac: edição e glossário (cód. ALC. 461)); e na versão espanhola do impresso de 1489, são $\mathrm{F} 1=58 \%$, F2 = 4\% e F3 = 38\% em um universo de 1.156 dados (CAMBRAIA. Demonstrativos nas traduções medievais espanholas do Libro Llamado Abbat Ysach). 
sistemas de demonstrativos em análise, convém examinar seu uso segundo tal aspecto, o que pode ser feito através da tabela abaixo ( $\mathrm{M}=$ masculino, $\mathrm{F}=$ feminino e $\mathrm{N}=$ neutro $)$ :

TABELA 2

Frequência por gênero

\begin{tabular}{|c|c|c|c|c|c|c|c|c|c|c|c|c|}
\hline \multirow{2}{*}{$\begin{array}{l}\text { Forma } \\
\text { Gênero }\end{array}$} & \multicolumn{3}{|c|}{ F1 } & \multicolumn{3}{|c|}{ F2 } & \multicolumn{3}{|c|}{ F3 } & \multicolumn{3}{|c|}{ Total } \\
\hline & M & F & $\mathbf{N}$ & M & F & $\mathrm{N}$ & M & F & $\mathrm{N}$ & M & F & $\mathrm{N}$ \\
\hline $\begin{array}{l}\text { NURC/ } \\
\text { SSA }\end{array}$ & - & - & - & $\begin{array}{r}26 / 65 \\
(40 \%) \\
\end{array}$ & $\begin{array}{l}22 / 65 \\
(34 \%) \\
\end{array}$ & $\begin{array}{l}17 / 65 \\
(26 \%) \\
\end{array}$ & $\begin{array}{l}11 / 44 \\
(25 \%) \\
\end{array}$ & $\begin{array}{r}33 / 44 \\
(75 \%) \\
\end{array}$ & - & $\begin{array}{r}37 / 109 \\
(34 \%) \\
\end{array}$ & $\begin{array}{r}55 / 109 \\
(50 \%) \\
\end{array}$ & $\begin{array}{r}17 / 109 \\
(16 \%) \\
\end{array}$ \\
\hline $\begin{array}{l}\text { NURC/ } \\
\text { RJ }\end{array}$ & - & - & & $\begin{array}{r}26 / 55 \\
(47 \%) \\
\end{array}$ & $\begin{array}{r}18 / 55 \\
(33 \%)\end{array}$ & $\begin{array}{l}11 / 55 \\
(20 \%)\end{array}$ & $\begin{array}{l}12 / 23 \\
(52 \%)\end{array}$ & $\begin{array}{r}11 / 23 \\
(48 \%)\end{array}$ & - & $\begin{array}{l}38 / 78 \\
(49 \%)\end{array}$ & $\begin{array}{r}29 / 78 \\
(37 \%)\end{array}$ & $\begin{array}{l}11 / 78 \\
(14 \%)\end{array}$ \\
\hline $\begin{array}{l}\text { NURC/ } \\
\text { SP }\end{array}$ & $\begin{array}{r}1 / 1 \\
(100 \%)\end{array}$ & - & - & $\begin{array}{l}28 / 82 \\
(34 \%)\end{array}$ & $\begin{array}{l}18 / 82 \\
(22 \%)\end{array}$ & $\begin{array}{l}36 / 83 \\
(44 \%)\end{array}$ & $\begin{array}{l}13 / 33 \\
(39 \%)\end{array}$ & $\begin{array}{r}13 / 33 \\
(39 \%)\end{array}$ & $\begin{array}{r}7 / 33 \\
(22 \%)\end{array}$ & $\begin{array}{r}42 / 116 \\
(36 \%)\end{array}$ & $\begin{array}{r}31 / 116 \\
(27 \%)\end{array}$ & $\begin{array}{r}43 / 116 \\
(37 \%)\end{array}$ \\
\hline $\begin{array}{l}\text { NURC/ } \\
\text { POA }\end{array}$ & $\begin{array}{r}1 / 4 \\
(25 \%)\end{array}$ & $\begin{array}{r}1 / 4 \\
(25 \%) \\
\end{array}$ & $\begin{array}{r}2 / 4 \\
(50 \%) \\
\end{array}$ & $\begin{array}{l}27 / 97 \\
(28 \%) \\
\end{array}$ & $\begin{array}{l}27 / 97 \\
(28 \%) \\
\end{array}$ & $\begin{array}{l}43 / 97 \\
(44 \%) \\
\end{array}$ & $\begin{array}{l}17 / 26 \\
(65 \%)\end{array}$ & $\begin{array}{r}6 / 26 \\
(23 \%) \\
\end{array}$ & $\begin{array}{r}3 / 26 \\
(12 \%) \\
\end{array}$ & $\begin{array}{r}45 / 127 \\
(35 \%)\end{array}$ & $\begin{array}{r}34 / 127 \\
(27 \%) \\
\end{array}$ & $\begin{array}{r}48 / 127 \\
(38 \%) \\
\end{array}$ \\
\hline $\begin{array}{l}\text { NURC/ } \\
\text { BR }\end{array}$ & $\begin{array}{r}2 / 5 \\
(40 \%)\end{array}$ & $\begin{array}{r}1 / 5 \\
(20 \%)\end{array}$ & $\begin{array}{r}2 / 5 \\
(40 \%)\end{array}$ & $\begin{array}{r}107 / 299 \\
(36 \%)\end{array}$ & $\begin{array}{r}85 / 299 \\
(28 \%)\end{array}$ & $\begin{array}{r}107 / 299 \\
(36 \%)\end{array}$ & $\begin{array}{r}53 / 126 \\
(42 \%)\end{array}$ & $\begin{array}{r}63 / 126 \\
(50 \%)\end{array}$ & $\begin{array}{r}10 / 126 \\
(8 \%)\end{array}$ & $\begin{array}{r}184 / 4301 \\
(43 \%)\end{array}$ & $\begin{array}{r}127 / 430 \\
(29 \%)\end{array}$ & $\begin{array}{r}119 / 430 \\
(28 \%)\end{array}$ \\
\hline $\begin{array}{l}\text { NURC/ } \\
\text { MX }\end{array}$ & $\begin{array}{r}9 / 23 \\
(39 \%)\end{array}$ & $\begin{array}{l}10 / 23 \\
(44 \%)\end{array}$ & $\begin{array}{r}4 / 23 \\
(17 \%)\end{array}$ & $\begin{array}{r}44 / 112 \\
(39 \%)\end{array}$ & $\begin{array}{r}45 / 112 \\
(40 \%)\end{array}$ & $\begin{array}{r}23 / 112 \\
(21 \%)\end{array}$ & - & $\begin{array}{r}1 / 1 \\
(100 \%)\end{array}$ & - & $\begin{array}{r}53 / 136 \\
(39 \%)\end{array}$ & $\begin{array}{r}56 / 136 \\
(41 \%)\end{array}$ & $\begin{array}{c}27 / 136 \\
(20 \%)\end{array}$ \\
\hline
\end{tabular}

Examinando primeiramente os dados relativos às diferentes cidades brasileiras, verifica-se um padrão interessante: a oposição gradual norte-sul constatada antes se apresenta novamente, mas agora mais claramente em dois blocos. Quanto a F2, ao norte (SSA e RJ) é menos utilizado no gênero neutro e ao sul (SP e POA) no gênero feminino (embora em POA formas masculinas e femininas tenham praticamente a mesma frequência). No que se refere a F3, ao norte (SSA e RJ) não há ocorrências no corpus e ao sul (SP e POA) há, mas em pouca quantidade. Analisando as frequências apenas por gênero, a referida divisão norte-sul se mantém: ao norte (SSA e RJ) formas neutras são as menos frequentes e ao sul (SP e POA) as femininas. Considerando os dados do Brasil conjuntamente, sobressaem a menor frequência de F2 no gênero feminino (como no grupo do sul) e a baixa frequência de F3 no neutro (como no grupo do norte). É realmente curioso o fato de parecer haver diferenças nos padrões de distribuição dos demonstrativos segundo a região: isso sugere que talvez esse sistema também seja relevante para caracterizar os diferentes falares do Brasil. 
Os dados de Pavani ${ }^{23}$ para SP apresentam a seguinte distribuição nos três tipos de inquérito: por forma, F1 $(\mathrm{M}=35 \%$, $\mathrm{F}=43 \%$ e $\mathrm{N}=22 \%), \mathrm{F} 2(\mathrm{M}=34 \%, \mathrm{~F}=29 \%$ e $\mathrm{N}=37 \%)$ e $\mathrm{F} 3$ $(\mathrm{M}=45 \%, \mathrm{~F}=37 \%$ e $\mathrm{N}=18 \%)$; em geral, $\mathrm{M}=37 \%, \mathrm{~F}=32 \% \mathrm{e}$ $\mathrm{N}=31 \%$. No caso de todo o conjunto de dados, percebe-se a mesma hierarquia $\mathrm{M}>\mathrm{F}>\mathrm{N}$ tanto no corpus de Pavani quanto no presente estudo, embora as formas femininas e neutras apresentem valores quase iguais em ambos os casos.

Como Castilho ${ }^{24}$ analisa a questão do gênero opondo conjuntamente formas masculinas e femininas a neutras, convém descrever o comportamento dos demonstrativos também segundo esse critério. Para os dados de SP, os resultados de Pavani ${ }^{25}$ $\mathrm{M} / \mathrm{F}=68 \%$ e $\mathrm{N}=31 \%$ - estão próximos aos da presente pesquisa - $\mathrm{M} / \mathrm{F}=63 \%$ e $\mathrm{N}=37 \%$. Para os dados do $\mathrm{RJ}$, os resultados encontrados por Roncarati ${ }^{26}$ - Amostra 80, M/F $=66 \%$ e N = 34\%; e Amostra 00, M/F $=60 \%$ e $\mathrm{N}=40 \%$ - estão um pouco distantes dos aqui apurados $-\mathrm{M} / \mathrm{F}=86 \%$ e $\mathrm{N}=14 \%$. Para os dados gerais do NURC/BR, os resultados apurados por Castilho (1993, p. 127 e 135$)-M / F=43 \%$ e $N=57 \%$ - também se distanciam um pouco dos aqui obtidos $-\mathrm{M} / \mathrm{F}=72 \%$ e $\mathrm{N}=28 \%$.

É interessante assinalar que, de forma geral, as formas neutras estão concentradas em F2: 77\% (301 de 391 ocs.) dos dados de SP de Pavani; ${ }^{27}$ 85\% (449 de 531 ocs.) na Amostra 80 e 81\% (662 de 818 ocs.) na Amostra 00 dos dados do RJ de Roncarati ${ }^{28} 87 \%$ (107 de 123 ocs.) dos dados do corpus compartilhado de

\footnotetext{
${ }^{23}$ PAVANI. Os demonstrativos este, esse e aquele no português culto falado em São Paulo, p. 27.

${ }^{24}$ CASTILHO. Os mostrativos no português falado.

${ }^{25}$ PAVANI. Os demonstrativos este, esse $e$ aquele no português culto falado em São Paulo, p. 27.

${ }^{26}$ RONCARATI, C. Os mostrativos na variedade carioca falada, p. 143.

${ }^{27}$ PAVANI. Os demonstrativos este, esse e aquele no português culto falado em São Paulo, p. 27.

${ }^{28}$ RONCARATI. Os mostrativos na variedade carioca falada, p. 143.
} 
Castilho; ${ }^{29}$ e 90\% (107 de 119 ocs.) nos dados gerais no presente estudo. A baixa frequência de formas neutras de F3 frente ao outros gêneros pode estar vinculada ao fato de poderem veicular valor negativo: como lembra Lapa, ${ }^{30}$ "o pronome aquilo admite em muitos casos uma significação claramente pejorativa". Tal uso se constata efetivamente no corpus analisado (embora não seja esse seu valor predominante) - veja-se o seguinte exemplo:

todo cara que é piloto de automóvel: é::deve ter algum parafuso frouxo (né?) porque aquilo é uma tentativa de suicídio dissimulada...porque normalmente::não passa::de três ou quatro anos e eles morrem mesmo né? (POA/DID008, linhas 258263; itálico nosso)

Os dados do EM mostram apenas uma tendência geral de menor frequência de formas neutras e de distribuição quase equânime entre masculinas e femininas, seja considerando F1 e F2 separadamente seja considerando-os conjuntamente.

O contraste entre os dados gerais do $\mathrm{PB}$ e os do EM revela uma mesma tendência de menor frequência de formas neutras ( $28 \%$ no português e $20 \%$ no espanhol). Uma diferença seria a prevalência de masculinas no PB e de femininas no EM (embora, neste caso, com valor muito próximo ao de masculinas).

\subsection{Frequência por posição no sintagma nominal}

Outro padrão que pode ser levado em conta para examinar uma possível perda de vitalidade de certas formas é a posição sintática dos demonstrativos. Pode-se verificar se esse aspecto é relevante para compreender o funcionamento dos sistemas de demonstrativos em análise através da tabela abaixo $(\mathrm{M}=$ margem; $\mathrm{N}=$ núcleo $)$ :

\footnotetext{
${ }^{29}$ CASTILHO. Os mostrativos no português falado, p. 135.

${ }^{30}$ LAPA. Estilística da língua portuguesa, p. 174.
} 
TABELA 3a

A frequência por posição no sintagma nominal

\begin{tabular}{l|r|r|r|r|r|r|r|r}
\hline Forma & \multicolumn{2}{|c|}{$\mathrm{F} 1$} & \multicolumn{2}{c|}{$\mathrm{F} 2$} & \multicolumn{2}{c|}{$\mathrm{F} 3$} & \multicolumn{2}{c}{ Total } \\
\hline Gênero & \multicolumn{1}{|c|}{$\mathrm{M}$} & \multicolumn{1}{c|}{$\mathrm{N}$} & \multicolumn{1}{c}{$\mathrm{M}$} & \multicolumn{1}{c}{$\mathrm{N}$} & \multicolumn{1}{c}{$\mathrm{M}$} & $\mathrm{N}$ & \multicolumn{1}{c}{$\mathrm{M}$} & \multicolumn{1}{c}{$\mathrm{N}$} \\
\hline NURC/BA & - & - & $37 / 65$ & $28 / 65$ & $23 / 44$ & $21 / 44$ & $60 / 109$ & $49 / 109$ \\
& & & $(57 \%)$ & $(43 \%)$ & $(52 \%)$ & $(48 \%)$ & $(55 \%)$ & $(45 \%)$ \\
\hline NURC/RJ & - & - & $38 / 55$ & $17 / 55$ & $19 / 23$ & $4 / 23$ & $57 / 78$ & $21 / 78$ \\
& & & $(69 \%)$ & $(31 \%)$ & $(83 \%)$ & $(17 \%)$ & $(73 \%)$ & $(27 \%)$ \\
\hline NURC/SP & - & $1 / 1$ & $36 / 82$ & $46 / 82$ & $24 / 33$ & $9 / 33$ & $60 / 116$ & $56 / 116$ \\
& & $(100 \%)$ & $(44 \%)$ & $(56 \%)$ & $(73 \%)$ & $(27 \%)$ & $(52 \%)$ & $(48 \%)$ \\
\hline NURC/POA & $2 / 4$ & $2 / 4$ & $46 / 97$ & $51 / 97$ & $17 / 26$ & $9 / 26$ & $65 / 127$ & $62 / 127$ \\
& $(50 \%)$ & $(50 \%)$ & $(47 \%)$ & $(53 \%)$ & $(65 \%)$ & $(35 \%)$ & $(51 \%)$ & $(49 \%)$ \\
\hline NURC/BR & $2 / 5$ & $3 / 5$ & $157 / 299$ & $142 / 299$ & $83 / 126$ & $43 / 126$ & $242 / 430$ & $188 / 430$ \\
& $(40 \%)$ & $(60 \%)$ & $(53 \%)$ & $(47 \%)$ & $(66 \%)$ & $(34 \%)$ & $(56 \%)$ & $(44 \%)$ \\
\hline NURC/MX & $19 / 22$ & $4 / 22$ & $87 / 112$ & $25 / 112$ & $1 / 1$ & - & $107 / 136$ & $29 / 136$ \\
& $(86 \%)$ & $(14 \%)$ & $(78 \%)$ & $(22 \%)$ & $(100 \%)$ & & $(79 \%)$ & $(21 \%)$ \\
\hline
\end{tabular}

Observando os dados por cidade, verificam-se: (a) o predomínio de $\mathrm{F} 2$ na margem em SSA e RJ mas no núcleo em SP e POA (repete-se, portanto, a divisão norte-sul vista nos itens anteriores); (b) o predomínio de $\mathrm{F} 3$ na margem em todas as cidades; e (c) o predomínio na margem de forma geral. Analisando os dados do PB em conjunto (NURC/BR), notam-se o predomínio de F1 no núcleo, uma leve vantagem de F2 na margem, o predomínio de F3 na margem e o predomínio da margem de forma geral. É interessante constatar que, justamente nas cidades em que há dados de F1 (SP e POA), F2 predomina no núcleo, ao contrário da tendência geral. A menor frequência de F3 no núcleo de forma geral deve resultar do já comentado fato de que aquilo, forma restrita à posição de núcleo, pode carregar valor negativo, razão pela qual seu uso apresentaria maiores restrições.

Os dados do EM mostram de forma sistemática o predomínio de demonstrativos na margem seja individualmente seja no conjunto.

Para tentar anular o efeito das formas neutras, que só podem ocorrer como núcleo, convém apresentar um novo quadro, com formas apenas do gênero masculino ou feminino: 
TABELA 3b

Frequência por posição no sintagma nominal (apenas gênero masculino e feminino)

\begin{tabular}{|c|c|c|c|c|c|c|c|c|}
\hline Forma & \multicolumn{2}{|c|}{ F1 } & \multicolumn{2}{|c|}{ F2 } & \multicolumn{2}{|c|}{ F3 } & \multicolumn{2}{|c|}{ Total } \\
\hline Gênero & $\mathbf{M}$ & $\mathrm{N}$ & M & $\mathrm{N}$ & M & $\mathrm{N}$ & M & $N$ \\
\hline NURC/BA & - & - & $\begin{array}{l}37 / 48 \\
(77 \%)\end{array}$ & $\begin{array}{c}11 / 48 \\
(23 \%)\end{array}$ & $\begin{array}{l}23 / 44 \\
(52 \%)\end{array}$ & $\begin{array}{l}21 / 44 \\
(48 \%)\end{array}$ & $\begin{array}{c}60 / 92 \\
(65 \%)\end{array}$ & $\begin{array}{l}32 / 92 \\
(35 \%)\end{array}$ \\
\hline NURC/RJ & - & - & $\begin{array}{l}38 / 44 \\
(86 \%)\end{array}$ & $\begin{array}{r}6 / 44 \\
(14 \%)\end{array}$ & $\begin{array}{l}19 / 23 \\
(83 \%)\end{array}$ & $\begin{array}{r}4 / 23 \\
(17 \%)\end{array}$ & $\begin{array}{l}57 / 67 \\
(85 \%)\end{array}$ & $\begin{array}{l}10 / 67 \\
(15 \%)\end{array}$ \\
\hline NURC/SP & - & $\begin{array}{r}1 / 1 \\
(100 \%) \\
\end{array}$ & $\begin{array}{l}36 / 46 \\
(78 \%)\end{array}$ & $\begin{array}{l}10 / 46 \\
(22 \%)\end{array}$ & $\begin{array}{l}24 / 26 \\
(92 \%)\end{array}$ & $\begin{array}{l}2 / 26 \\
(8 \%) \\
\end{array}$ & $\begin{array}{l}60 / 73 \\
(82 \%) \\
\end{array}$ & $\begin{array}{l}13 / 73 \\
(18 \%) \\
\end{array}$ \\
\hline NURC/POA & $\begin{array}{r}2 / 2 \\
(100 \%)\end{array}$ & - & $\begin{array}{l}46 / 54 \\
(85 \%)\end{array}$ & $\begin{array}{r}8 / 54 \\
(15 \%)\end{array}$ & $\begin{array}{l}17 / 23 \\
(74 \%)\end{array}$ & $\begin{array}{r}6 / 23 \\
(26 \%)\end{array}$ & $\begin{array}{l}65 / 79 \\
(82 \%)\end{array}$ & $\begin{array}{l}14 / 79 \\
(18 \%)\end{array}$ \\
\hline NURC/BR & $\begin{array}{r}2 / 3 \\
(67 \%)\end{array}$ & $\begin{array}{r}1 / 3 \\
(33 \%)\end{array}$ & $\begin{array}{r}157 / 192 \\
(82 \%)\end{array}$ & $\begin{array}{r}35 / 192 \\
(18 \%)\end{array}$ & $\begin{array}{r}83 / 116 \\
(72 \%)\end{array}$ & $\begin{array}{r}33 / 116 \\
(28 \%)\end{array}$ & $\begin{array}{r}242 / 311 \\
(78 \%)\end{array}$ & $\begin{array}{r}69 / 311 \\
(22 \%)\end{array}$ \\
\hline NURC/MX & $\begin{array}{r}19 / 19 \\
(100 \%)\end{array}$ & - & $\begin{array}{l}87 / 89 \\
(98 \%)\end{array}$ & $\begin{array}{l}2 / 89 \\
(2 \%)\end{array}$ & $\begin{array}{r}1 / 1 \\
(100 \%)\end{array}$ & - & $\begin{array}{r}107 / 109 \\
(98 \%)\end{array}$ & $\begin{array}{r}2 / 109 \\
(2 \%)\end{array}$ \\
\hline
\end{tabular}

É interessante verificar que, eliminando-se as formas do gênero neutro (que só podem ocupar a posição de núcleo), emerge um padrão bastante geral de predominância dos demonstrativos no gênero masculino e feminino na margem: no quadro anterior, F1, mesmo com suas poucas ocorrências, já era categórico no núcleo em SP e ocupava metade das ocorrências nessa posição em POA; já F2 tinha predominado (ainda que levemente) no núcleo em SP e POA.

Os dados do EM apenas do gênero masculino e feminino continuam a apresentar, como na tabela anterior, uma predominância de demonstrativos na margem, com a diferença de essa predominância dar-se de forma ainda mais intensa neste caso: os 79\% de margem na Tabela 3a passam a 98\% na Tabela 3b.

Verifica-se, portanto, que tanto no PB quanto no EM os demonstrativos, especificamente as formas que podem ocorrer na margem ou no núcleo do sintagma nominal (ou seja, masculinas e femininas), ocorrem predominantemente na margem. Não se pode deixar de salientar que essa predominância na margem é mais intensa no EM (79\% na tabela 3 a e $98 \%$ na Tabela $3 b)$ do que no PB (56\% na tabela $3 a$ e $78 \%$ na Tabela $3 b)$. 
Essa predominância na margem parece indicar que a função primordial dos demonstrativos seria a de estabelecer a coesão referencial como determinantes, ficando provavelmente a tarefa de estabelecer essa coesão como núcleo de sintagma nominal sob responsabilidade de outras formas, como os pronomes pessoais. ${ }^{31}$

Ainda sobre a questão da posição dos demonstrativos no sintagma nominal, convém assinalar que, quando na margem, ocorrem predominantemente à esquerda, embora tenham sido constatados dois casos, tanto nos dados do PB quanto nos do EM, em que ocorrem à direita - vejam-se a seguir esses casos na fala dos informantes:

Envolve um juiz...que é o encarregado de dirimir as as dúvidas surgidas durante a partida...e é...é realizada numa...numa quadra...quadra essa que tem u/ éh...em cada...uma de suas...extremidades um objetivo um alvo... (RJ/DID012, linhas 792-798; itálico nosso)

o jogo de tênis se realiza também numa quadra... dividida ao meio por uma rede...ao rés do chão...é...e o objetivo também é de marcar tentos...tentos esses que me parece que são marcados quando: o...o

\footnotetext{
${ }^{31}$ A historiografia gramatical de língua portuguesa permite recuperar interpretações interessantes sobre os demonstrativos (CAMBRAIA. Demonstrativos: história de uma categoria na tradição gramatical de língua portuguesa (sécs. XVI a XIX)): (i) pronomes pessoais e demonstrativos, que parecem ser complementares no estabelecimento de coesão referencial (o primeiro na posição de núcleo e o segundo na posição de margem), já foram considerados há muito uma só classe: João de Barros os classificou conjuntamente como demonstrativos na sua gramática de 1540 (BARROS. Gramática da língua portuguesa, p. 20); e (ii) já a interpretação de que os demonstrativos estão vinculados às pessoas do discurso parece ser, ao contrário, doutrina recente, pois um dos primeiros a postular esse vínculo no domínio lusófono parece ter sido BARBOSA (Grammatica philosophica da lingua portugueza, p. 162).
} 
jogador não consegue...éh:...rebater determinadas bolas arremessadas pelo adversário (RJ/DID012, linhas 807-812; itálico nosso)

En el lapso entre que estuve trabajando en esta compañía americana y me había salido del despacho, estuve como entrenador de natación, y me volvió a dar la cosa esa por abajo otra vez, pero salí adelante (...) (MX/DID092, p. 19; itálico nosso)

Enc. - ¿Cuántas horas son de estudio?

Inf. - iEn la carrera esta? Vienen siendo como unas cuarenta y cuatro, cuarenta y seis horas semanales, considerando laboratorios. (MX/DID158, p. 24; itálico nosso)

A posposição do demonstrativo no $\mathrm{PB}$ parece ser um fenômeno bastante raro: no corpus aqui analisado ocorreu apenas nos dados do RJ, está restrita a F2 e corresponde a apenas 1\% (2 de 157 ocs.) dos dados de F2 na margem conjuntamente nos gêneros masculino e feminino. Pavani, ${ }^{32}$ não registra nenhum caso de posposição nos seus dados do NURC/SP e sugere que seja um padrão mais próprio da linguagem escrita. Castilho ${ }^{33}$ assinala que $25 \%$ (23 de 91 ocs.) dos seus dados do corpus compartilhado do NURC foram nessa posição e assinala que nesses casos houve sempre a repetição do nome (do antecedente), fato que se constata igualmente nos dois dados do $\mathrm{PB}$ acima transcritos. Considerando que nesse corpus compartilhado há três tipos de inquérito, podese aventar a hipótese de que, justamente nos tipos de inquérito não analisados na presente pesquisa $\left(\right.$ EFs e $\mathrm{D}_{2}$ ), a posposição seja menos rara (é possível, aliás, que seja mais comum nas EFs, pois parece ter uma conotação de maior formalidade).

\footnotetext{
${ }^{32}$ PAVANI. Os demonstrativos este, esse $e$ aquele no português culto falado em São Paulo, p. 32-33.

${ }^{33}$ CASTILHO. Os mostrativos no português falado, p. 131.
} 
Também a posposição do demonstrativo no EM parece ser rara. Embora tenha tido uma ocorrência em cada um dos dois inquéritos analisados, correspondem a uma frequência muito baixa: 5\% (1 de 19 ocs.) dos dados de F1 na margem conjuntamente nos gêneros masculino e feminino e $1 \%$ ( 1 de 87 ocs.) dos de F2. Segundo Llorach, ${ }^{34}$ quando o demonstrativo aparece posposto ao nome, perde sua função identificadora e, para recuperá-la, exige a presença do artigo no sintagma nominal (p. ex., el chico este); além disso, agregaria ao conteúdo global do grupo um valor enfático ou afetivo, que nem sempre é pejorativo ou irônico. Lavric ${ }^{35}$ considera que a posposição seria na verdade um indicador de indexicalidade, ou seja, sinal de um contexto consabido a reconstruir ou ainda de uma informação prévia que o locutor não está totalmente seguro de poder pressupor em seu ouvinte. A proposta de Lavric parece pertinente para o segundo dos exemplos do EM, no qual a posposição parece ocorrer justamente com a função de o falante certificar-se de que ele e o outro interlocutor estão tratando exatamente da mesma coisa (no caso, a carreira profissional). Já o primeiro exemplo do EM parece ser melhor explicado pela ideia de valor pejorativo, já que o informante relata que sua atuação como treinador de natação (retomada justamente por "la cosa esa") teve um desenvolvimento negativo ("dar...por abajo"), razão pela qual a abandonou.

Contrastando os dados do PB e do EM, verifica-se que, embora ambas as línguas aceitem posposição de demonstrativo, trata-se de processos bem distintos: no português, a posposição não desencadeia a exigência de artigo (aliás, não é possível sua presença) e parece ocorrer estritamente com a função de especificar o antecedente através de acréscimo de alguma característica sua, estando possivelmente restrita a contextos mais formais e à modalidade escrita; já no espanhol, a posposição desencadeia a

${ }^{34}$ LLORACH. Gramática de la lengua española, p. 90.

${ }^{35}$ LAVRIC. Aquellos misteriosos demostrativos pospuestos, p. 112. 
exigência de artigo e apresenta distintas funções, tais como a afetiva (expressando julgamento negativo) e a de indicador de indexicalidade (assegurando que os interlocutores estão tratando do mesmo referente).

A ausência de referência à posposição de demonstrativo em fases mais pretéritas do português ${ }^{36}$ parece sugerir tratar-se de uma estrutura relativamente recente na língua portuguesa. $\mathrm{O}$ exemplo mais antigo encontrado até agora na literatura especializada foi o citado por Dias, ${ }^{37}$ extraído de obra de Antônio Feliciano de Castilho (1800-1875): "a madrugada, o sol, e a lua com a alegria, com os resplendores, com a devoção, coisas estas todas de Deus, mas rudes e sem entendimento". ${ }^{38}$ Através de pesquisa na base do Corpus do Português (www.corpusdoportugues.org), obtiveram-se mais evidências de que os dados mais antigos parecem ser do século XIX e, examinando os dados dessa base, pôde-se aventar a hipótese de que a estrutura com demonstrativo posposto derive de reanálise de estruturas em que predicativo (substantivo) e sujeito (demonstrativo) aparecem em contato e nessa ordem (como em exclamações), as quais acabam por ser interpretadas como um só sintagma nominal - partindo de exemplo com a frase "Que homem este!" extraída d'Os Fidalgos da Casa Mourisca (1871) de Júlio Dinis (1839-1871), pode-se propor o seguinte trajeto de reanálise: [[Que homem] [este]] > [Que [homem este]] > [Homem este].

\footnotetext{
${ }^{36}$ MATTOS E SILVA. Estruturas trecentistas, p. 153-173; NUNES, J. J. Compêndio de gramática histórica portuguesa: fonética e morfologia, p. 245-250; COUTINHO. Pontos de gramática bistórica, p. 256-258; WILLIAMS. Do latim ao português, p. 161-163; HUBER. Gramática do português antigo, p. 192-194; PEREIRA. Grammatica histórica, p. 402-407.

${ }^{37}$ DIAS. Syntaxe histórica portuguesa, p. 70-71.

${ }^{38}$ CASTILHO. Quadros históricos de Portugal, t. II, p. 23 (itálico nosso).
} 


\subsection{Busca lexical e truncamento}

Roncarati ${ }^{39}$ assinala a ocorrência de dois empregos de demonstrativos em seu corpus que refletem o processamento linguístico-cognitivo: trata-se de usos que indicam busca lexical (como reflexo de reativação ou resgate de referentes na memória episódica) ou que constituem truncamento de sequências discursivas.

Como esclarecido anteriormente, não se incluíram nas tabelas acima as ocorrências de demonstrativos nesses tipos de estruturas. Foram poucas essas ocorrências, ${ }^{40}$ mas uma análise sua é capaz de indicar questões de interesse para a compreensão dos princípios que regem o uso dos demonstrativos.

Em muitos casos, o demonstrativo é simplesmente repetido até que o informante se decida sobre a proposição a ser feita (casos de busca lexical) - vejam-se dois exemplos abaixo:

então...esse seria é esta esta esta gama assim de pessoas de pessoal que sai eh que vai para o magistério primário deveria ser MUIto bem remunerado pra que pudesse especializar (POA/DID008, linhas 529-533; itálico nosso)

o fundamental em todo esporte é aquele...está naquele aforismo latino que diz mens sana in corpore sano (RJ/DID012, linhas 565-566; itálico nosso)

Enquanto no primeiro exemplo a repetição de demonstrativo finaliza com uma mesma estrutura (um sintagma nominal), já no segundo há uma reelaboração em que se passa de um sintagma nominal para um sintagma preposicionado, caso em que a busca lexical se associa a um truncamento.

\footnotetext{
${ }^{39}$ RONCARATI. Os mostrativos na variedade carioca falada, p. 155-157.

${ }^{40}$ A ocorrência de busca lexical ou truncamento na fala dos informantes por entrevista foi a seguinte: MX/DID092: 0 oc.; MX/DID138: 8 ocs.; SSA/DID277: 1 oc.; SSA/DID138: 2 ocs.; RJ/DID012: 10 ocs.; SP/DID018: 1 oc.; SP/DID161: 6 oc.; POA/DID008: 4 ocs.; e POA/DID008: 6 ocs.
} 
Os casos, porém, mais interessantes envolvem um tipo muito curioso de hesitação:

até se houver regulados de voltagem, também, se estiver com defeito, pode ser mudado. Pode ser mudado aqueles... os botões reguladores; tem um nome especial, mas na hora não me ocorre. (SSA/ DID138, linhas 613-617; itálico nosso)

Nesse dado, nota-se uma hesitação entre o emprego de demonstrativo e de artigo definido, prevalecendo a opção final pelo artigo definido. Essa hesitação revela uma grande afinidade entre os artigos definidos e os demonstrativos (sobretudo F3), sugerindo que o estudo destes deva ser em algum momento relacionado ao daqueles. Não se pode pensar, no entanto, que a hesitação leve necessariamente à opção pelo artigo definido, pois há dados em que opção final foi pelo demonstrativo:

ela inclusive... inclusive na na...nessa linguagem de crônica desportiva... que é bastante é bastante rica... ela tem uma série de outros nomes (RJ/DID012, linhas 856-858; itálico nosso)

Essa grande afinidade entre artigos definidos e demonstrativos torna-se ainda mais evidente quanto se verifica que em alguns casos parece haver identidade funcional entre eles:

A sinalização de trânsito...poderia dizer que a gente tem dois tipos: a sinalização vertical, que são aquelas placas colocadas em poste ou mesmo em...em locais próprios, e a sinalização horizontal, que seria $a$ sinalização de rua, desenho de faixa contínua ou interrompida e desenho de faixas pra pedestres (SSA/DID277, linhas 506-512; itálico nosso)

No exemplo acima há repetição de estrutura quase idêntica de relativa com verbo de ligação e predicativo, mas, no primeiro item da enumeração, utiliza-se no predicativo o 
demonstrativo (“aquelas placas...") e, no segundo item, o artigo definido ("a sinalização...”). Não é muito evidente a razão de haver demonstrativo no primeiro mas definido no segundo, mas parece existir uma certa diferença de grau de definitude: os demonstrativos parecem apenas sugerir a existência de um conhecimento partilhado, enquanto o definido assumiria como certa a existência desse conhecimento. É interessante que no início das duas enumerações há artigo definido ("a sinalização vertical" e "a sinalização horizontal"), o que sugere que o grau de definitude deveria ser o mesmo na estrutura seguinte, que explicita essas enumerações (ou seja, na oração relativa). É necessário examinar com mais detalhe ocorrências desse tipo (com presença de demonstrativo e artigo definido em estruturas semelhantes) para verificar se a diferença está realmente no grau de definitude.

Pelo exposto acima, vê-se que os dados de busca lexical ou de truncamento não devem ser interpretados como sinal de agramaticalidade da fala, mas sim, segundo propôs Labov, ${ }^{41}$ como expressão do processo de elaboração de ideias. Mas mais importante do que isso é constatar que a análise da gênese de proposições na língua falada é capaz de revelar pistas sobre a organização de componentes da língua, tal como foi o caso de se ter identificado como artigos definidos e demonstrativos concorrem frequentemente entre si, o que indica uma forte vínculo entre essas categorias.

\subsection{Uso fático}

Nos dados do EM da presente pesquisa, como já se disse, o demonstrativo este ocorre com um uso particular, sendo chamado por Kany ${ }^{42}$ de elemento de preenchimento ("elemento de relleno")

\footnotetext{
${ }^{41}$ LABOV. Sociolinguistic patterns, p. 203.

${ }^{42}$ KANY. Sintaxis hispanoamericana, p. 171.
} 
e por Benítez ${ }^{43}$ de uso fático, ${ }^{44}$ termo este mais adequado por evidenciar sua função. Esse tipo de uso está presente, segundo Kany ${ }^{45}$ em várias regiões de fala hispano-americana, como Cuba, Venezuela, Equador, Chile, Argentina e Uruguai; e Beníte $z^{46}$ assinala sua existência também no espanhol de Porto Rico e, com menor frequência, no espanhol madrilenho. Trata-se naturalmente de um fenômeno bastante distinto de simples casos de repetição de demonstrativo (como descrito na seção anterior), ainda que não se possa descartar a hipótese de que sua gênese tenha sido a partir desse processo de repetição. Constata-se que se trata de fenômeno particular pelo fato de ocorrer em posições na estrutura frasal em que o demonstrativo não seria pertinente - vejam-se dois exemplos abaixo:

me habían rajado con una...este...navaja la llanta del carro, y, posteriormente... pues tuve ciertas fricciones con ellos (MX/DID092, p. 17; itálico nosso)

Le dí gracias a Dios como no te puedes imaginar, y consecuentemente...pues, este ... salí airoso de esa ocasión. (MX/DID092, p. 18; itálico nosso)

No primeiro exemplo vê-se a ocorrência de este fático no meio de um sintagma nominal feminino (sem relação com o substantivo, portanto) e no segundo nota-se sua combinação com pues, outro elemento que também assume função fática. O este fático tem uma frequência digna de nota: são 25 ocorrências. contra 9 ocs. não fáticas

\footnotetext{
${ }^{43}$ BENÍTEZ. La deixis demostrativa en la lengua hablada de Madrid y de San Juan de Puerto Rico, p. 557.

${ }^{44}$ Nos dados do PB, essa função costuma ser exercida pela forma é (transcrita no NURC como $e b$, provavelmente pelo fato de os responsáveis pela transcrição não considerarem que seja o verbo de ligação com nova função, embora a hipótese de ser originalmente o verbo pareça ser a mais provável).

${ }^{45}$ KANY. Sintaxis hispanoamericana, p. 171-172.

${ }^{46}$ BENÍTEZ. La deixis demostrativa en la lengua hablada de Madrid y de San Juan de Puerto Rico, p. 557-558.
} 
de F1 conjuntamente nas duas amostras de informantes e 10 ocs. contra nenhuma não fática de F1 na fala dos documentadores. Benítez ${ }^{47}$ registra 820 ocs. (dentre 4.153 dados) de demonstrativos não dêiticos no espanhol de Porto Rico, dos quais $95 \%$ são de uso fático, correspondendo, portanto, a cerca de $20 \%$ de todas as ocorrências de demonstrativos, enquanto os dados para o espanhol madrilenho apresentam 150 ocs. (dentre 5.365 dados) de demonstrativos não dêiticos, dos quais $75 \%$ são de uso fático, correspondendo a aproximadamente $2 \%$ de todas as ocorrências. Nos dados do corpus do EM aqui analisado verifica-se uma porcentagem de $15 \%$ do conjunto (contabilizando-se as 25 ocs. de fáticos na fala dos informantes com as demais 136). Vê-se, portanto, que os dados do EM se aproximam mais nesse aspecto do espanhol portoriquenho do que do madrilenho.

Arechalde ${ }^{48}$ contrastando um corpus de dados apenas de uso fático do EM culto com um do popular, verificou que ele é bem mais frequente no segundo caso ( $24 \%$ na fala culta contra $76 \%$ na fala popular), algo compatível com suas expectativas, uma vez que, como assinala a pesquisadora, trata-se de um uso estigamatizado pelo ensino formal. Verificou ainda que há diferenças quanto ao gênero do informante: na fala culta, $67 \%$ das ocs. estão em informantes do sexo masculino, mas apenas 33\% no feminino; já na popular, $42 \%$ em informantes do sexo masculino e $58 \%$ no feminino. Vê-se, portanto, que se trata de um fenômeno sensível ao grau de formalidade e ao gênero do informante.

\footnotetext{
${ }^{47}$ BENíTEZ. La deixis demostrativa en la lengua hablada de Madrid y de San Juan de Puerto Rico, p. 557.

${ }^{48}$ ARECHALDE. El uso de este... en el habla de la Ciudad de México.
} 


\section{Considerações finais}

O presente estudo exploratório sobre os demonstrativos nos corpora do NURC brasileiro e mexicano permitiu a identificação de uma série de fatos interessantes sobre o uso dessas formas, sendo os principais fatos os seguintes:

a) há evidência de tendência ao binarismo em ambos os domínios linguísticos, mas com prevalência de F2 e F3 no PB e de F1 e F2 no EM;

b) em ambos os domínios, prevalece F2;

c) em ambos os domínios, formas neutras tendem a ser menos frequentes, com destaque para F3 (a que apresenta menor frequência nesse gênero);

d) em ambos os domínios, demonstrativos masculinos e femininos tendem a ser mais frequentes na posição de margem (esquerda) no sintagma nominal;

e) parece haver uma relação entre o padrão de uso dos demonstrativos no $\mathrm{PB}$ e uma divisão entre uma região mais ao norte (SSA/RJ) e uma mais ao sul (SP/POA), havendo, portanto, indício de que possa ser um fator para delimitação de áreas linguísticas no Brasil; e

f) há no EM um uso particular dos demonstrativos (uso fático) aparentemente ausente do PB.

Os presentes resultados precisam ser futuramente testados em corpora mais amplos: com maior número de ocorrências, em diferentes tipos de inquéritos, de informantes de gênero masculino e feminino e de diferentes faixas etárias. Apresentou-se, porém, neste trabalho, um conjunto de fatos interessantes que devem guiar uma nova seleção desses corpora mais amplos.

Uma tarefa que naturalmente é essencial para o prosseguimento de uma análise como a aqui apresentada é a classificação das formas segundo suas funções. Não foi feita aqui por se considerar que ainda não há uma tipologia precisa e explicitamente descrita que dê conta dessas funções. $O$ fato de se ter verificado que os demonstrativos estão funcionalmente relacionados a 
artigos definidos e a pronomes pessoais (os três etimologicamente derivados praticamente de uma mesma matriz latina, originalmente demonstrativa) sugere que uma descrição coerente do uso dos demonstrativos deverá necessariamente, em algum momento, integrá-los em um sistema mais amplo de estratégias de referenciação, abordagem esta compatível com o postulado de Givón ${ }^{49}$ (2001) de que uma descrição linguística deve considerar as estruturas preferencialmente pela função e não pela forma.

Resumen: Los sistemas de demostrativos en lenguas románicas presentan de forma general una tendencia al binarismo, aunque esa tendencia no es atingida a través de los mismos caminos y los resultados no son iguales. En el presente trabajo, se analisan los demostrativos en datos de lengua hablada extraídos de diálogos entre informante y encuestador del Proyecto NURC de cuatro ciudades brasileñas y de la ciudad de México y se demuestra la presencia de la referida tendencia al binarismo en ambos los domínios lingüísticos.

Palabras-llave: Lingüística románica; demostrativos; portugues brasileño; español mexicano; lengua hablada.

\section{Referências}

ARECHALDE, M. A. S. El uso de este... en el habla de la Ciudad de México. In: ESPINOZA, A. V. (Org.). ACTAS DEL XIV CONGRESO INTERNACIONAL DE ALFAL (MONTERREY, 17-21 DE OCTUBRE 2005), Santiago de Chile: ALFAL, 2006. Disponível em: <http:// www.mundoalfal.org/cdcongreso/cd/dialectologia_sociolinguistica/ soler.html > .

${ }^{49}$ GIVÓN. Syntax: an introduction, p. 23, v. I. 
BARBOSA, J. S. Grammatica philosophica da lingua portugueza. Lisboa: Typographia da Academia Real das Sciencias, 1822.

BARROS, J. de. Gramática da língua portuguesa. 3. ed. Ed. de José Pedro Machado. Lisboa: [s. n.], 1957.

BENÍTEZ, I. Y. R. La deixis demostrativa en la lengua hablada de Madrid y de San Juan de Puerto Rico. In: ALONSO, C. H. et al. (Ed.). El español de América. Salamanca: Junta de Castilla y León, 1991. p. 551-559.v. 1.

BLANCH, J. M. L. El habla de la ciudad de México. México: UNAM, 1971.

CALLOU, D.; LOPES, C. R. (Org.). A linguagem falada culta na cidade do Rio de Janeiro. Rio de Janeiro: Faculdade de Letras da UFRJ, 1993. v. II: Diálogos entre informante e documentador.

CÂMARA JR, J. M. História e estrutura da língua portuguesa. 4. ed. Rio de Janeiro: Padrão, 1985.

CAMBRAIA, C. N. Livro de Isaac: edição e glossário (cód. ALC. 461). 2000. Tese (Doutorado em Filologia e Língua Portuguesa) - FFLCHUSP, São Paulo, 2000.

CAMBRAIA, C. N. Demonstrativos nas traduções medievais espanholas do Libro Llamado Abbat Ysach. In: AMARAL, E. T. R.; BARROS, C. S.; VIEIRA, E. M. A.; ROJO, S. (Orgs.). Anais do V Congresso Brasileiro de Hispanistas / I Congresso Internacional da Associação Brasileira de Hispanistas. Belo Horizonte : Faculdade de Letras da UFMG, 2009. p. 2380-2388. Disponível em <http://www.letras.ufmg.br/espanhol/Anais/ anais_paginas_\%202010-2501/Demonstrativos\%20nas\%20tradu\%E7\% F5es.pdf $>$.

CAMBRAIA, C. N. O caos na norma: demonstrativos em gramáticas tradicionais. Belo Horizonte, 2008b. (Comunicação apresentada na VIII Semana de Eventos da Faculdade de Letras, na Universidade Federal de Minas Gerais, em Belo Horizonte, no período de $1^{\circ}$ a 5 de outubro de 2008).

CAMBRAIA, C. N. Demonstrativos: história de uma categoria na tradição gramatical de língua portuguesa (sécs. XVI a XIX). Évora, 2009. (Comunicação apresentada no II Simpósio Mundial de Estudos de Língua Portuguesa, na Universidade de Évora, em Évora (Portugal), no período de 6 a 11 de outubro de 2009). 
CAMBRAIA, C. N.; BIANCHET, S. M. G. Caleidoscópio latino-românico: demonstrativos. Cadernos de Letras da UFF, Niterói, n. 35, p. 15-35, 2008. Disponível em: < http://www.uff.br/cadernosdeletrasuff/35/ artigo2.pdf $>$.

CAMBRAIA, C. N. et al. Variação, mudança e estilística: demonstrativos. In: LIMA-HERNANDES, M. C. et al. (Org.). A língua portuguesa no mundo. São Paulo: FFLCH-USP, 2008. Disponível em: < http:// www.fflch.usp.br/eventos/simelp/new/pdf/post/04.pdf $>$.

CASTILHO, A. F. de. Quadros históricos de Portugal. Lisboa: Typ. da Sociedade Propagadora dos Conhecimentos Úteis, 1838.

CASTILHO, A. T. de. Os mostrativos no português falado. In: CASTILHO, A. T. de (Org.). Gramática do português falado: as abordagens. Campinas: Editora UNICAMP, 1993. p. 119-147.v. 3.

CID, O.; COSTA, M. C.; OLIVEIRA, C. T. Este e esse na fala culta do Rio de Janeiro. Estudos Lingüísticos e Literários, Salvador, n. 5, p. 195-208, 1986.

COUTINHO, I. de L. Pontos de gramática histórica. 6. ed. 3. reimpr. Rio de Janeiro: Acadêmica, 1970.

DIAS, A. E. da S. Syntaxe histórica portuguesa. Lisboa: Clássica, 1918.

GIVÓN, T. Syntax: an introduction. Amsterdam/Philadelphia: John Benjamins, 2001.

HILGERT, J. G. (Org.). A linguagem falada culta na cidade de Porto Alegre. Porto Alegre: Editora de UPF / Editora UFRGS, 1997. v. 1: Diálogos entre informante e documentador.

HUBER, J. Gramática do português antigo. Lisboa: Fundação Calouste Gulbenkian, 1986.

KANY, C. E. Sintaxis hispanoamericana. 2. reimpr. Madrid: Gredos, 1994. LABOV, W. Sociolinguistic patterns. Philadelphia: University of Philadelphia Press, 1972a.

LABOV, W. Language in the inner city. Philadelphia: University of Philadelphia Press, 1972b.

LAPA, M. R. Estilística da língua portuguesa. Lisboa: Seara Nova, 1945. 
LAVRIC, E. Aquellos misteriosos demostrativos pospuestos. In: CICHON, P. et al. (Ed.). ACTAS DE LAS PRIMERAS JORNADAS DE HISPANISTAS EN AUSTRIA (Wien, 19-20 de mayo 1995). Wien: Praesens, 1996. p. 106-113.

LLORACH, E. A. Gramática de la lengua española. Madrid: Espasa Calpe, 2000.

MATTOS E SILVA, R. V. Estruturas trecentistas. Lisboa: Imprensa Nacional-Casa da Moeda, 1989.

MOLLICA, M. C.; BRAGA, M. L. (Org.). Introdução à sociolingüística: o tratamento da variação. 2. ed. São Paulo: Contexto, 2004.

MOTA, J.; ROLLENBERG, V. (Org.). A linguagem falada culta na cidade de Salvador. Salvador: Editora UFBA, 1994. v. I : Diálogos entre informante e documentador.

NASCENTES, A. Êste, êsse. In: AZEVEDO FILHO, L. A. de. Miscelânea filológica em honra à memória do professor Clóvis Monteiro. Rio de Janeiro: Ed. do Professor, 1965.

NUNES, J. J. Compêndio de gramática histórica portuguesa: fonética e morfologia. 9. ed. Lisboa: Clássica, 1989.

PAVANI, S. Os demonstrativos este, esse $e$ aquele no português culto falado em São Paulo. 1987. Dissertação (Mestrado em Linguística) UNICAMP, Campinas, 1987.

PEREIRA, E. C. Grammatica historica. 6. ed. São Paulo: Companhia Editora Nacional, 1929.

PRETI, D.; URBANO, H. (Org.). A linguagem falada culta na cidade de São Paulo. São Paulo: T. A. Queiroz, 1988. v. III: Diálogos entre informante e documentador.

RONCARATI, C. Os mostrativos na variedade carioca falada. In: PAIVA, M. da C.; DUARTE, M. E. L. (Org.). Mudança lingüística em tempo real. Rio de Janeiro: Contra Capa, 2003.

WILLIAMS E. B. Do latim ao português. 4. ed. Rio de Janeiro: Tempo Brasileiro, 1991.

Recebido para publicação em janeiro de 2009. Aprovado em março de 2009. 